\title{
Mobilizações indígenas e legislações indigenistas no Ceará
}

\section{Setecentista/Oitocentista}

COSTA, João Paulo Peixoto. Na lei e na guerra: políticas indígenas e indigenistas no Ceará (I798-I845). Teresina: EdUFPI, 20I8, 43Ip.

\section{Adauto Santos da Rocha*}

O minado campo de disputas envolvendo o protagonismo da escrita e, consequentemente, as escolhas assumidas ao longo do percurso acadêmico, continua a colocar em "prova de fogo" a relevância histórica de diversas obras produzidas sobre os povos indígenas no Brasil, e, essencialmente, na Região Nordeste. O exotismo buscado por vários pesquisadores coloca em questão a legitimidade das mobilizações em busca de direitos, amparadas em legislações e vultosos eventos militares ocorridos entre os séculos XVIII e XIX, definidores do Estado nacional brasileiro.

Não faria sentido, pois, escrever uma história indígena ou tratar os índios na História, desvencilhando-a do presente, mesmo sendo remetida aos últimos dois séculos, diante da ausência de imparcialidade na escrita, em grande medida, utilizada como instrumento de denúncia às injustiças sociais ocorridas com os "silenciados" e "soterrados" pelas narrativas hegemônicas. A partir de "novas lentes", o texto ora resenhado, procurou evidenciar a participação dos indígenas como protagonistas da/na história, através de um fecundo e frondoso caminho fragmentado, micro-histórico.

O livro do professor João Paulo Peixoto Costa trata do envolvimento de indígenas da então Província do Ceará em importantes conflitos ocorridos no Brasil entre fins do século XVIII e meados do XIX. A questão que transcende o texto é a de como os indígenas agiram a partir de interesses próprios, aliando-se a outros povos e ao poder estatal, em momentos oportunos, para colocar em prática a capacidade de socialmente construir a autonomia, inclusive territorial, mobilizados pelos diferentes usos em cargos políticos e militares no Ceará Setecentista/Oitocentista.

\footnotetext{
* Mestre em História na Universidade Federal de Campina Grande (UFCG), vinculado a linha de pesquisas: Cultura, poder e identidades. Tem se dedicado a pesquisar as mobilizações dos indígenas Xukuru-Kariri e os processos sócio-históricos de migrações para trabalho no século XX. Integra o Grupo de Pesquisas em História Indígena de Alagoas (GPHIAL) e realiza pesquisas sobre os povos indígenas em Alagoas desde 2015.
} 


\section{C) GitistóróRICA}

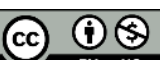

Com ampla pesquisa documental em distintos e importantes acervos históricos do Brasil e do exterior, como o Arquivo Histórico Ultramarino (AHU); o Arquivo Nacional (AN); o Arquivo Público do Estado do Ceará (APEC); o Arquivo Público do Estado do Piauí (APEPI) e a Biblioteca Nacional (BN), o livro, ora publicado pela Editora da Universidade Federal do Piauí (EdUFPI), foi, originalmente, uma Tese de doutorado em História Social defendida na Universidade Estadual de Campinas (UNICAMP), em 2016.

Acertadamente, a obra foi dividida em duas partes. A primeira delas, "Na Lei", composta por quatro capítulos, discutiu as relações entre os indígenas na Província do Ceará e a legislação vigente nos citados períodos históricos. No primeiro capítulo, o autor tratou sobre a permanência do Diretório dos Índios em território cearense, desconstruindo a consolidada tese do "vazio legislativo", demonstrando cabalmente que, na ausência de uma legislação atualizada, os parâmetros anteriores serviriam como atenuantes para regular os aldeamentos indígenas, no caso específico, o "vazio legislativo" foi "preenchido" pela continuidade do Diretório, abolido oficialmente em I830, reestabelecido no Ceará em I843.

No segundo capítulo, foram discutidas as vinculações entre a atuação extraoficial do Diretório dos Índios no Ceará e a formação do Estado nacional brasileiro, com a extinção dos cargos militares indígenas e o gradativo desamparo estatal com a independência do Brasil, colocando em suspeição anteriores "garantias" de liberdade, autonomia e cidadania a grupos marginalizados. Os indígenas, alinhavados aos anseios do antigo monarca português seriam súditos do novo reinado? Que lugar ocupavam no desenvolvimento da nação? Seriam eles cidadãos brasileiros? Distante do espectro da nacionalidade unificada, o autor tentou evidenciar os interesses particulares a cada província, ou, pelo menos, às elites provinciais com relação às populações indígenas.

No terceiro capítulo, o autor discorreu sobre a participação legislativa indígena no conjunto normativo e o "espaço social imaginado" para os índios no Império recém instituído nas Américas, limitando a autonomia, liberdade e cidadania dos indígenas, fornecedores de mão de obra e aumentativos do poderio exercidos pelos potentados, cujo interesse principal, além da exploração do trabalho, fora a usurpação territorial.

No capítulo quatro, foi analisado o jogo de interesses entre os diversos atores políticos e sociais no cotidiano da Província do Ceará, como os fazendeiros, integrantes do governo e os indígenas. Tornava-se evidente a tentativa de tutelar os povos indígenas a partir de alterações legislativas associadas aos transitórios períodos no estrato social do império. Os "vassalos" da Coroa portuguesa, foram transformados em "súditos" após a independência do Brasil, categoria ilegítima para os indígenas, devido ao auto reconhecimento como 


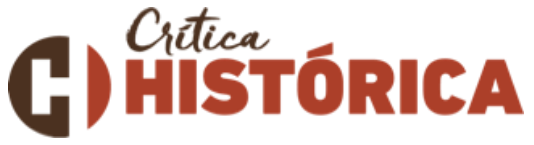

“cidadãos" brasileiros, camada que previa a ilegalidade da tutela e legítima posse territorial, embora estivessem despossuídos de garantias fidedignas judicialmente, ao tempo em que eram notórias as invasões de fazendeiros nos territórios indígenas, face a arena de disputas montada com a negligência e/ou omissão do Estado.

A segunda parte do livro, "Na guerra", também composta por quatro capítulos, analisou as estratégias utilizadas para o efetivo recrutamento militar dos índios entre o Antigo Regime português e o recém-formado Estado nacional brasileiro. Foi interesse do autor, evidenciar as relações estabelecidas entre os indígenas, a Província do Ceará e as conexões militares com unidades provinciais adjacentes.

O quinto capítulo centrou-se nas discussões sobre o recrutamento dos indígenas no Ceará em "Corpos de Ordenança", onde, pelo caráter ambíguo do exercício militar, o soldado indígena assumia atribuições militares e atuava como mão de obra, devido a inviabilidade de combater em localidades distantes dos aldeamentos. A proeminente participação indígena como força militar e de trabalho resultou na concessão de mercês e honrarias, inclusive, hereditariamente, pelo reconhecimento dos serviços bélicos prestados à monarquia ibérica, continuados com a presença de vilas de índios que deveriam representar a legislação portuguesa nos sertões da colônia.

No sexto capítulo, foi tratada a participação indígena em diversos e notáveis cargos militares. Reiteradamente foram suscitados debates, a partir das fontes consultadas, sobre as destacadas patentes ocupadas por cumprirem os desígnios da Coroa e atenderem, até certo ponto, às façanhas e interesses particulares dos subordinados aldeados. A formação de "uma elite indígena" pôs em oposição os interesses pessoais de prestígio militar e equidade social nos aldeamentos. Na prática, a atuação indígena nas Revoltas oitocentistas e em tantos outros eventos bélicos pode ser entendida como a formação de grupos produtivos e subordinados à "sua majestade". Além do comando militar, cabia aos oficiais indígenas organizar socialmente as vilas, estimular e fiscalizar frentes de trabalho, para incentivar a produção econômica.

O capítulo sétimo, analisou o envolvimento indígena nos críticos momentos políticos brasileiros, ocorridos entre I82I e I825, tratados pelo autor como "guerras de independência". Tratara-se de redefinir a autonomia e liberdade dos chamados "grupos subalternos", atribuindo, pois, um novo significado a autonomia e liberdade, conceitos tão caros aos aldeamentos cearenses, sobretudo, pela indefinida posse territorial. Uma aliança com a vizinha Província do Piauí para expulsar os apoiadores das Cortes portuguesas e defender a Independência, pôs em operacionalidade o recrutamento de "voluntários". Embora tenham 


\section{C) Hitistór RICA}

sido negligenciados por uma vasta produção bibliográfica sobre o tema, alguns grupos de recrutados indígenas combateram os opositores apoiadores dos portugueses, com precários armamentos e ausência de preparo militar em decisivas batalhas pela independência, como a de Jenipapo, por exemplo. A participação indígena no processo da Independência não resultou de manipulações por agentes externos, a dimensão social os colocava em meio a uma "guerra" que também era deles.

O oitavo e último capítulo discorreu sobre o envolvimento dos indígenas na Província do Ceará em insurreições liberais oitocentistas: a Revolução Pernambucana de I8I7, a Confederação do Equador de I824 e a Balaiada, entre I839 e I84I. Chamados de "valorosos vassalos", foram convocados pelo poder provincial para debelar o insuflado movimento liberal pernambucano contra a crescente cobrança tributária exercida pela Coroa para a manutenção dos gastos exorbitantes praticados no Rio de Janeiro, então Capital do Império. Em oposição às garantias territoriais indígenas, as elites de Fortaleza e o recém coroado Dom Pedro II, propunham o acúmulo agrário e ameaçavam a autonomia dos aldeamentos cearenses.

As desagradáveis ambições foram agravantes para a formação de alianças entre os indígenas na Província do Ceará com os revoltosos pernambucanos, líderes da Confederação do Equador, movimento revolucionário contestatório que propôs a instauração de um governo republicano em Pernambuco, que seria fortalecido com o enfraquecimento do absolutismo imperial.

Após alguns meses, a Confederação foi sucumbida pelo contra-ataque imperial, deixando os indígenas da Província do Ceará sem escolhas. A aliança com o governo imperial foi atenuada com a promessa de "moderação" nas ações anti-indígenas, embora o fim da Confederação do Equador tenha fortalecido as invasões aos territórios indígenas no Ceará, marcadas por expulsões e limitações no pleno direito da cidadania.

No caso da Balaiada, ocorrida na Província do Maranhão, os revoltosos, compostos por grupos socialmente desprestigiados, reivindicavam justiça para os desmandos políticos e abusos de poder na região. Por serem o elo mais fraco, a precarização trabalhista e as difíceis condições de vida encorparam o movimento revoltoso. Insatisfeitos com as injustiças sociais e avanço dos latifundiários, os indígenas na Província do Ceará apoiaram os insurgentes maranhenses, cujos grupos de agricultores, de acordo com a documentação analisada pelo autor, poderia ter considerável quantidade de "índios da Ibiapaba" que haviam migrado para o Maranhão em períodos de longas estiagens. Sufocado entre I840 e I84I, o movimento revolucionário reverteu os indígenas revoltosos em "recrutados" 


\section{C) Hitistór RICA}

compulsórios para a Armada Imperial. A categoria de cidadãos não atendeu aos anseios dos índios que, viram a formação do Estado nacional receosamente como uma maneira de excluí-los do processo da cidadania, e, portanto, negando-lhes legítimos direitos.

Nesse livro, do jovem e promissor pesquisador João Paulo, os índios na Província do Ceará não foram vistos como "meros fantoches" a mercê e aos desígnios das autoridades provinciais e imperiais. Os distintos interesses no processo legislativo e as façanhas militares indígenas, a partir de uma minuciosa revisão bibliográfica e análise documental, atribuíram novos sentidos para antigos conceitos historiográficos, como o "vazio institucional" pós Diretório Pombalino, que, como bem evidenciou o autor, manteve-se em vigor na Província do Ceará até meados do século XIX.

Distanciado do "congelamento" historiográfico, o autor demonstrou que os eventos históricos ocorridos no século XIX pelas diversas províncias do Nordeste, não ocorreram dissociados de negociações, legislações e conflitos. A proposta de um estudo pormenorizado analisou as entranhas e a rede de conexões entre a Província do Ceará, as circunvizinhas e o Império do Brasil, considerando os indígenas como importante engrenagem nos rumos e funcionamento da nação.

Nos últimos 30 anos, vários pesquisadores em História, Antropologia e ciências afins, passaram a estudar os índios como protagonistas, e, portanto, partícipes dos processos históricos nacionais e internacionais. A ampliação nas dimensões historiográficas e as abordagens conectadas com outros campos do conhecimento contribuíram para a formação da Antropologia Histórica, perspectiva metodológica muito bem desempenhada pelo autor.

Para além de uma produção historiográfica vertida na compilação de informações, as análises realizadas pelo autor demonstraram a profundidade em escrever operando a partir de diferentes escalas. O livro publicado perpassa a produção doutoral, assumindo um caráter inovador do ponto de vista metodológico, desconstruindo espaçadas e malversadas situações históricas e decisões estatais que colocavam sob suspeição o lugar ocupado pelos indígenas nas guerras do Oitocentos e nas discussões políticas do Império do Brasil.

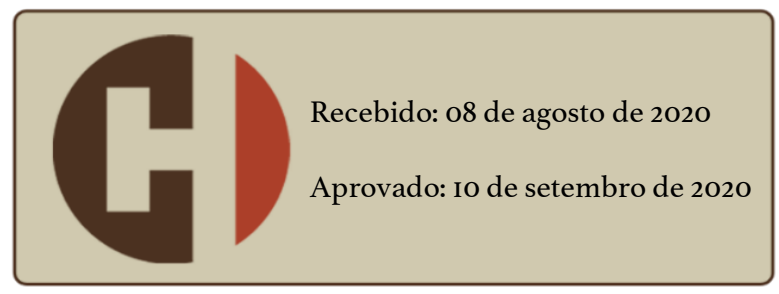

